\title{
Volatile composition of wines from cvs. Blanco lexítimo, Agudelo and Serradelo (Vitis vinifera) grown in Betanzos (NW Spain)
}

\author{
Mar Vilanova ${ }^{1,4}$, Zlatina Genisheva ${ }^{2}$, Lorenzo Bescansa ${ }^{3}$, Antón Masa ${ }^{1}$ \\ and José M. Oliveira ${ }^{2}$
}

\begin{abstract}
J. Inst. Brew. 115(1), 35-40, 2009

Wine aroma is formed by volatile compounds of different chemical natures and origins. Betanzos is the most northern viticole geographic area from Galicia (NW Spain). The aromatic profiles of wines produced from two white varieties (Blanco lexítimo and Agudelo) and one red variety (Serradelo) from Betanzos, harvested in 2006 and 2007, have been established by gas chromatography (GC/FID). A total of 35 varietal and fermentative aroma compounds were identified and quantified in free volatile form, which include terpenols, $\mathrm{C}_{13}$-norisoprenoids, alcohols, esters, volatile fatty acids and volatile phenols. To ascertain the compounds with major impact odours, the Odour Activity Value $(O A V)$ was calculated. Twelve compounds showed concentrations above their perception threshold $(O A V>1)$. The results obtained suggest that ethyl octanoate (apple), isoamyl acetate (banana), ethyl hexanoate (fruity) and $\beta$-damascenone (floral) were the most powerful odorants for the white wines Blanco lexítimo and Agudelo from Betanzos. Ethyl octanoate and $\beta$-damascenone (fruity and floral aroma respectively) were the most odorant for the red wine Serradelo.
\end{abstract}

Key words: Agudelo, Blanco lexítimo, GC-FID, Serradelo, Vitis vinifera, volatile compounds.

\section{INTRODUCTION}

Wine aroma is formed by volatile compounds of different chemical natures and origins and they vary as a function of grape metabolism, variety and also certain cultural and climate-related factors ${ }^{27}$. Although a great number of volatile aroma compounds are found in grapes, most of those found in wine are formed during fermentation by the yeast Saccharomyces cerevisiae ${ }^{29}$. The effects of malolactic fermentation on the volatiles of wine has been the subject of controversy, but it is now generally

\footnotetext{
${ }^{1}$ Misión Biolóxica de Galicia (CSIC). PO Box 28, 38080, Pontevedra (España).

${ }^{2}$ IBB-Institute for Biotechnology and Bioengineering, Centre of Biological Engineering, Universidade do Minho, 4710-057 Braga (Portugal).

${ }^{3}$ Adega Lorenzo Bescansa S.U.L. Betanzos (Spain).

${ }^{4}$ Corresponding author. Email: mvilanova@mbg.cesga.es
}

Publication no. G-2009-0327-570

(C) 2009 The Institute of Brewing \& Distilling agreed that specific wine attributes are altered and that complexity is enhanced through the appearance of unique flavours and odours ${ }^{11,28}$.

Among the compounds responsible for wine aroma are terpenols, $\mathrm{C}_{13}$-norisoprenoides, alcohols, esters, acids and volatile phenols ${ }^{1,7,24}$. Monoterpenols and $\mathrm{C}_{13}$-norisoprenoids are characteristics of the grape, forming the varietal aroma of wines. Some of these volatile compounds are modified during yeast fermentation ${ }^{13}$. The secondary aromas, produced by yeast metabolism during fermentation include esters, acetates, alcohols and others.

The content of aromatic compounds of grapes makes it possible to classify the varieties into neutrals or aromatics $^{16}$. The importance of these aromatic compounds depends not only on their concentration, but also on their olfactory perception thresholds, defined as the lowest concentration that can be detected by smelling ${ }^{5,17}$. The concentration/threshold ratio, known as "odour activity value" $(O A V)$, shows the contribution of a specific compound to the aroma of a wine. Compounds with an $O A V>1$ are considered to have an active contribution ${ }^{3,23}$. However, this does not take into account the depressive or synergic odour effects resulting from the interactions of the different molecules present in the wines, but it can serve as a first approximation to the potential contribution of each compound to the global aroma $a^{6,18 .}$

During the last few years, there has been a growing interest in the recuperation of the denominated autochthonous varieties from Galicia. This is the case with the traditional grape varieties grown in Betanzos. Betanzos is an ancient winemaking area situated in the most northern viticole geographic area from Galicia (NW Spain). White cultivar Blanco lexítimo and Agudelo and red cultivar Serradelo are three Vitis vinifera grape varieties traditionally grown in Betanzos. As far as we know, aroma composition of wines from these cultivars has not yet been studied.

This paper reports the results of the first study on volatile composition of the monovarietal wines produced with $c v$. Blanco lexítimo, Agudelo and Serradelo grown in the same geographic area and made under the same fermentation conditions during two consecutive vintages (2006 and 2007). The main objective of this study was to identify and quantify the principal volatile compounds present in the wines of these cultivars and contribute to their characterization according to the aromatic profile. 
Odour Activity Values $(O A V)$ were calculated in order to know the most potent aroma compounds of the wines studied.

\section{MATERIALS AND METHODS}

\section{Grapes and wines}

Two white grape varieties from Vitis vinifera, Blanco lexítimo and Agudelo and one red grape variety, Serradelo, grown in Betanzos (Galicia) from 2006 and 2007 vintages were considered in this study.

Monovarietal wine production was carried out in the Bescansa Winery from Betanzos. The white and red wines were prepared in $100 \mathrm{~L}$ Inox tanks. Spontaneous fermentation was realized at $18^{\circ} \mathrm{C}$ and $28^{\circ} \mathrm{C}$, for white and red musts respectively and using standard winemaking practices. After fermentation the wines were filtered and transferred to $0.75 \mathrm{~L}$ bottles. The bottles were stopped and stored at $6^{\circ} \mathrm{C}$ until analysis two months after fermentation.

Ethanol, total acidity, volatile acidity, reducing sugars, $\mathrm{pH}$ and tartaric and malic acid contents of wines were determined according to OIV Official Methods ${ }^{20}$.

\section{Extraction of wine volatiles}

In a $10 \mathrm{~mL}$ culture tube (Pyrex, ref. 1636/26MP), $8 \mathrm{~mL}$ of wine, $2.4 \mu \mathrm{g}$ of internal standard (4-nonanol, Merck ref. 818773$)$ and a magnetic stir bar $(22.2 \mathrm{~mm} \times 4.8 \mathrm{~mm})$ were added. Extraction was done by stirring the sample with dichloromethane (Merck, ref. 1.06054) according Oliveira et $\mathrm{al}^{22}$. After cooling at $0^{\circ} \mathrm{C}$ during $10 \mathrm{~min}$, the magnetic stir bar was removed and the organic phase was removed using centrifugation $\left(R C F=5118,5 \mathrm{~min}, 4^{\circ} \mathrm{C}\right)$ and the extract recovered into a vial, using a Pasteur pipette. The aromatic extract $(200 \mu \mathrm{L})$ was dried with anhydrous sodium sulphate (Merck, ref. 1.06649) and placed into a new vial ${ }^{22}$. Extractions of volatiles from each wine were carried out in triplicate.

\section{GC-FID analysis}

A Chrompack CP-9000 gas chromatograph equipped with a split/splitless injector and a flame ionization detector (FID) with a capillary column, coated with CP-Wax 52 CB (50 m $\times 0.25 \mathrm{~mm}$ i.d., $0.2 \mu \mathrm{m}$ film thickness, Chrompack), was used. The temperature of the injector and detector were both set to $250^{\circ} \mathrm{C}$. The oven temperature was held at $40^{\circ} \mathrm{C}$, for $5 \mathrm{~min}$, then programmed to rise from $40^{\circ} \mathrm{C}$ to $235^{\circ} \mathrm{C}$, at $3^{\circ} \mathrm{C} \mathrm{min} \mathrm{m}^{-1}$, and then finally programmed from $235^{\circ} \mathrm{C}$ to $255^{\circ} \mathrm{C}$, at $5^{\circ} \mathrm{C} \mathrm{min}{ }^{-1}$. The carrier gas was helium 55 (Praxair) at $103 \mathrm{kPa}$ and the split vent was set to $13 \mathrm{~mL} / \mathrm{min}$. Each $3 \mu \mathrm{L}$ extract was injected in splitless mode (for $15 \mathrm{~s}$ ). Quantification of volatiles, as 4nonanol equivalents, was performed with Varian MS Workstation version 6.6 by comparing retention indices with those of pure standard compounds ${ }^{22}$.

\section{Odour activity value}

To evaluate the contribution of a chemical compound to the aroma of a wine the Odour Activity Value (OAV) was calculated as the ratio between the concentration of compound and the perception threshold found in the literature $^{5,17,25,30}$.

\section{Statistical analyses}

To establish the relationship between the aromas and the wines elaborated with different Betanzos cultivars, principal component analysis ( $P C A)$ was carried out. The calculations were performed using the Enterprise Guide 3 System Software (SAS Institute, Cary, NC, USA).

\section{RESULTS AND DISCUSSION}

Table I shows results for ethanol, total acidity, volatile acidity, reducing sugars, $\mathrm{pH}$ and tartaric acid of wines obtained from Blanco lexítimo, Agudelo and Serradelo varieties harvested in 2006 and 2007. All wines were fermented to dryness. The ethanol and acidity of the wines were very different for 2006 than for the 2007 vintages. The ethanol of the wines was higher in the 2006 than the 2007 vintage. Moreover, the 2007 vintage showed important levels of total acidity. Probably the climatic conditions were the principal factor that explains the existence of differences between years, in the general composition of wines from Betanzos, in the two years studied. This indicates that the degree of maturation was possibly incomplete in the 2007 vintage.

The volatile composition of monovarietal wines from Blanco lexítimo, Agudelo and Serradelo is shown in Table II. The data are expressed as the mean $(\mu \mathrm{g} / \mathrm{L})$ of the GC analyses of triplicate extractions. A total of 35 compounds were identified and quantified in the 2006 and 2007 vintages, 4 monoterpenic alcohols, $1 \mathrm{C}_{13}$-norisoprenoid, 7 alcohols, 11 esters, 7 volatile fatty acids and 5 volatile phenols. The represented compounds were chosen regarding their olfactive impact in Loureiro and Alvarinho wines from Portugal ${ }^{23}$, i.e., compounds with $O A V>0.1^{10,17}$.

The total concentration of free volatile compounds was very different in the two vintages. White wine Blanco lexítimo had $28784.7 \mu \mathrm{g} / \mathrm{L}$ and $16808.2 \mu \mathrm{g} / \mathrm{L}$ of free volatiles in the 2006 and 2007 vintage, respectively, whereas the white wine Agudelo had 29945.3 $\mu \mathrm{g} / \mathrm{L}$ and 13881.1 $\mu \mathrm{g} / \mathrm{L}$ and the red wine Serradelo $25899.1 \mu \mathrm{g} / \mathrm{L}$ and $13710.1 \mu \mathrm{g} / \mathrm{L}$. There were large differences in total volatile concentration between the two vintages. The results for volatile composition varied between vintages for the same variety and could have been strongly influenced by weather factors such as temperature and rainfall during ripening, fermentation conditions and the yeast involved ${ }^{4,19}$.

Alcohols were quantitatively the largest group of the volatile compounds in Blanco lexítimo, Agudelo and Serradelo wines from 2006 vintage $(45.8 \%, 49.5 \%$ and $59.5 \%$ respectively) and 2007 vintage $(38.6 \%, 60.8 \%$ and

Table I. Chemical composition of wines from Blanco lexítimo, Agudelo and Serradelo from Betanzos (2006 and 2007 vintage).

\begin{tabular}{|c|c|c|c|c|c|c|}
\hline & \multicolumn{2}{|c|}{$\begin{array}{l}\text { Blanco } \\
\text { lexítimo }\end{array}$} & \multicolumn{2}{|c|}{ Agudelo } & \multicolumn{2}{|c|}{ Serradelo } \\
\hline & 2006 & 2007 & 2006 & 2007 & 2006 & 2007 \\
\hline Ethanol (\% vol) & 12.8 & 12.0 & 11.7 & 10.6 & 11.0 & 11.1 \\
\hline Total acidity (g/L) & 5.7 & 7.9 & 5.6 & 10.1 & 5.4 & 7.9 \\
\hline Volatile acidity $(\mathrm{g} / \mathrm{L})$ & 0.5 & 0.3 & 0.5 & 0.5 & 0.6 & 0.3 \\
\hline Reducing sugars $(\mathrm{g} / \mathrm{L})$ & 0.8 & $<1.0$ & $<1.0$ & $<1.0$ & 0.5 & $<1.0$ \\
\hline $\mathrm{pH}$ & 3.1 & 3.4 & 3.3 & 3.0 & 3.2 & 3.0 \\
\hline Tartaric acid (g/L) & 3.5 & 2.6 & 2.9 & 2.3 & 3.0 & 3.7 \\
\hline Malic acid (g/L) & $<0.3$ & 3.8 & $<0.3$ & 5.4 & $<0.3$ & 2.2 \\
\hline
\end{tabular}


$75 \%$ respectively) (Fig. 1). Alcohols are produced by yeast metabolism during alcoholic fermentation and play an important role in the flavour of the wines depending of the type of compounds and their concentration ${ }^{31}$. Among varietal compounds, four monoterpenols and one $\mathrm{C}_{13^{-}}$ norisoprenoid were identified in the wines from Betanzos. Linalool, which has a floral aroma and low perception threshold, was quantitatively the main terpenol in Blanco lexítimo wine from the two vintages, 2006 and 2007, representing $73.6 \%$ and $85.8 \%$ respectively of the total terpenols analyzed. Similar results have been reported by other authors ${ }^{23}$ for the Loureiro variety from Vinhos Verdes in Portugal, where linalool represented $75 \%$ of the total monoterpenic concentration, followed by Alvarinho, Avesso, Amaral and Vinhão. For Serradelo from the 2006 vintage, $\alpha$-terpineol was the most important terpenol at $20.3 \mu \mathrm{g} / \mathrm{L}$ and it accounted for $41 \%$ of the total monoterpenic concentration. Nerol and $\beta$-damascenone were important varietal compounds in the Serradelo wines from the 2006 vintage.

With regard to fermentative compounds, alcohols and esters were lower in 2007 for the three wines studied; however, volatile phenols were higher in 2007 for Blanco lexítimo and Agudelo. Given that the fermentation conditions were the same, the differences in the wine composition may be attributed to the different must compositions between vintages.

Volatile phenols were high in Serradelo wines from the 2006 vintage, where 4-ethylphenol represented $86.6 \%$ of phenols analysed. Phenols present in young wines arise both from the grapes and from yeast metabolism².

In terms of the number of compounds quantified, esters represent the largest group (11 compounds). Table II shows ethyl hexanoate, ethyl lactate and diethyl succinate as having the highest concentrations in the 2006 vintage for the Blanco lexítimo and Agudelo wines. Similar results were found with the volatile composition of the Zalema white wines ${ }^{9}$. Isoamyl acetate showed the highest concentration from the three wines from the 2007 vintage.

Among volatile fatty acids, the concentration of octanoic acid was the highest for the three wines, Blanco lexitimo, Agudelo and Serradelo, from the two vintages studies.

Two PCAs were used to identify the aromas that discriminated best among the wines of the different varieties

Table II. Volatile composition of wines (mean of three replicates in $\mu \mathrm{g} / \mathrm{L}$ ) from Blanco lexítimo, Agudelo and Serradelo cultivars in consecutive vintages 2006 and 2007.

\begin{tabular}{|c|c|c|c|c|c|c|c|c|c|}
\hline & \multicolumn{3}{|c|}{ Blanco lexítimo } & \multicolumn{3}{|c|}{ Agudelo } & \multicolumn{3}{|c|}{ Serradelo } \\
\hline & 2006 & 2007 & Mean \pm SD & 2006 & 2007 & Mean \pm SD & 2006 & 2007 & Mean \pm SD \\
\hline \multicolumn{10}{|l|}{ Terpenols } \\
\hline Linalool & 27.0 & 25.5 & $26.2 \pm 1.1$ & 2.4 & 2.3 & $2.3 \pm 0.1$ & 14.5 & 13.4 & $13.9 \pm 0.8$ \\
\hline$\alpha$-Terpineol & 4.4 & 2.9 & $3.6 \pm 1.1$ & 3.1 & 1.8 & $2.5 \pm 1.0$ & 20.3 & 3.5 & $11.9 \pm 11.9$ \\
\hline Citronellol & 4.4 & 0.2 & $2.3 \pm 3.0$ & nd & 2.4 & - & 5.6 & 1.5 & $3.6 \pm 2.9$ \\
\hline Nerol & 1.0 & 1.2 & $1.1 \pm 0.1$ & nd & nd & - & 9.2 & 0.8 & $5.0 \pm 5.9$ \\
\hline \multicolumn{10}{|l|}{$\mathrm{C}_{13}$-Norisoprenoids } \\
\hline$\beta$-Damascenone & 1.9 & 0.8 & $1.3 \pm 0.7$ & 1.9 & 1.1 & $1.5 \pm 0.5$ & 5.1 & 1.6 & $3.35 \pm 2.5$ \\
\hline \multicolumn{10}{|l|}{ Alcohols } \\
\hline 1-Propanol & 81.0 & 102.8 & $91.9 \pm 15.4$ & 110.4 & 37.2 & $73.8 \pm 51.7$ & 74.7 & 35.8 & $55.3 \pm 27.5$ \\
\hline 2-Methyl-1-propanol & 868.2 & 1142.6 & $1005.4 \pm 194.1$ & 1018.4 & 1068.5 & $1043.5 \pm 35.4$ & 1679.2 & 1296.4 & $1487.8 \pm 270.7$ \\
\hline 1-Butanol & 20.5 & 15.8 & $18.2 \pm 3.3$ & 23.5 & 3.9 & $13.7 \pm 13.9$ & 10.3 & 5.3 & $7.8 \pm 3.5$ \\
\hline 3-Methyl-1-pentanol & 22.4 & 17.6 & $20.0 \pm 3.4$ & 42.4 & 17.6 & $30.0 \pm 17.5$ & 11.9 & 23.6 & $17.8 \pm 8.3$ \\
\hline 1-Hexanol & 208.4 & 449.0 & $328.7 \pm 170.1$ & 834.6 & 534.5 & $684.5 \pm 212.2$ & 1080.4 & 1102.8 & $1091.6 \pm 15.8$ \\
\hline 3-(Methylthio)propanol & 95.0 & 30.6 & $62.8 \pm 45.6$ & 55.8 & 45.9 & $50.9 \pm 7.0$ & 75.6 & 52.0 & $63.8 \pm 16.7$ \\
\hline 2-Phenylethanol & 11903.4 & 4739.1 & $8321.2 \pm 5065.9$ & 12740.3 & 6735.0 & $9737.7 \pm 4246.3$ & 12466.9 & 7767.0 & $10116.9 \pm 3323.4$ \\
\hline \multicolumn{10}{|l|}{ Esters } \\
\hline Ethyl butyrate & 121.5 & 154.2 & $137.8 \pm 23.1$ & 165.5 & 86.8 & $126.2 \pm 55.7$ & 112.0 & 83.6 & $97.8 \pm 20.1$ \\
\hline Ethyl 2-methylbutyrate & 7.7 & 0.2 & $4.0 \pm 5.3$ & 13.4 & 1.4 & $7.4 \pm 8.5$ & 6.7 & 0.9 & $3.8 \pm 4.1$ \\
\hline Ethyl 3-methylbutyrate & 15.1 & 0.9 & $8.0 \pm 10.0$ & 21.6 & 2.6 & $12.1 \pm 13.5$ & 5.9 & 1.7 & $3.8 \pm 3.0$ \\
\hline Isoamyl acetate & 268.3 & 1888.6 & $1078.5 \pm 1145.8$ & 203.5 & 1371.1 & $787.3 \pm 825.6$ & 141.3 & 460.7 & $301.0 \pm 225.8$ \\
\hline Ethyl hexanoate & 462.1 & 349.8 & $406.0 \pm 79.4$ & 429.2 & 209.3 & $319.3 \pm 155.5$ & 123.2 & 204.9 & $164.1 \pm 57.7$ \\
\hline Hexyl acetate & 9.2 & 138.2 & $73.7 \pm 91.2$ & 13.6 & 80.1 & $46.8 \pm 47.0$ & 2.5 & 29.3 & $15.9 \pm 18.9$ \\
\hline Ethyl lactate & 4722.8 & 201.6 & $2462.2 \pm 3197.0$ & 5754.2 & 103.7 & $2929.0 \pm 3995.5$ & 3541.9 & 135.3 & $1838.6 \pm 2408.8$ \\
\hline Ethyl octanoate & 820.2 & 784.7 & $802.4 \pm 25.1$ & 717.5 & 247.5 & $482.5 \pm 332.3$ & 139.3 & 234.2 & $186.7 \pm 67.1$ \\
\hline Ethyl decanoate & 173.8 & 93.7 & $133.8 \pm 56.7$ & 158.7 & 18.8 & $88.8 \pm 98.9$ & 34.0 & 31.5 & $32.8 \pm 1.7$ \\
\hline Diethyl succinate & 1749.2 & 48.3 & $898.7 \pm 1202.7$ & 1801.7 & 49.1 & $925.4 \pm 1239.3$ & 3452.6 & 73.6 & $1763.1 \pm 2389.3$ \\
\hline 2-Phenylethyl acetate & 118.1 & 267.6 & $192.9 \pm 105.7$ & 61.8 & 130.9 & $96.4 \pm 48.8$ & 34.0 & 73.7 & $53.9 \pm 28.0$ \\
\hline \multicolumn{10}{|l|}{ Volatile fatty acids } \\
\hline 2+3-Methylbutyric acid & 49.2 & 49.9 & $49.6 \pm 0.5$ & 95.1 & 64.5 & $79.8 \pm 21.6$ & 27.1 & 31.7 & $29.4 \pm 3.3$ \\
\hline Butyric acid & 506.7 & 353.8 & $430.2 \pm 108.1$ & 803.9 & 179.0 & $491.5 \pm 441.9$ & 962.7 & 201.1 & $581.9 \pm 538.5$ \\
\hline Hexanoic acid & 957.7 & 1098.4 & $1028.1 \pm 99.5$ & 945.9 & 469.2 & $707.5 \pm 337.1$ & 281.9 & 379.0 & $330.5 \pm 68.7$ \\
\hline Octanoic acid & 4191.1 & 4083.6 & $4137.4 \pm 76.0$ & 3782.1 & 2042.6 & $2912.4 \pm 1230.0$ & 809.8 & 1226.3 & $1018.0 \pm 294.5$ \\
\hline Decanoic acid & 1229.2 & 605.4 & $917.3 \pm 441.1$ & 33.0 & 218.4 & $125.7 \pm 131.1$ & 280.0 & 227.4 & $253.7 \pm 37.2$ \\
\hline Dodecanoic acid & 39.9 & 36.8 & $38.4 \pm 2.2$ & 59.0 & 5.2 & $32.1 \pm 38.0$ & 18.5 & 7.3 & $12.9 \pm 7.9$ \\
\hline \multicolumn{10}{|l|}{ Volatile phenols } \\
\hline Guaiacol & 4.2 & nd & - & nd & nd & - & 0.7 & nd & - \\
\hline 4-Ethylphenol & 52.0 & nd & - & 7.5 & 2.0 & $4.7 \pm 3.9$ & 409.0 & nd & - \\
\hline 4-Vinylguiacol & 6.7 & 35.8 & $22.6 \pm 18.7$ & 15.4 & 29.8 & $22.6 \pm 10.2$ & 5.2 & nd & - \\
\hline 4-Vinylphenol & 4.2 & 63.8 & $34.0 \pm 42.2$ & 11.4 & 110.8 & $61.1 \pm 70.3$ & 51.8 & nd & - \\
\hline Vanillin & 38.2 & 24.7 & $31.5 \pm 9.5$ & 18.4 & 8.1 & $13.2 \pm 7.2$ & 5.4 & 4.5 & $5.0 \pm 0.6$ \\
\hline
\end{tabular}



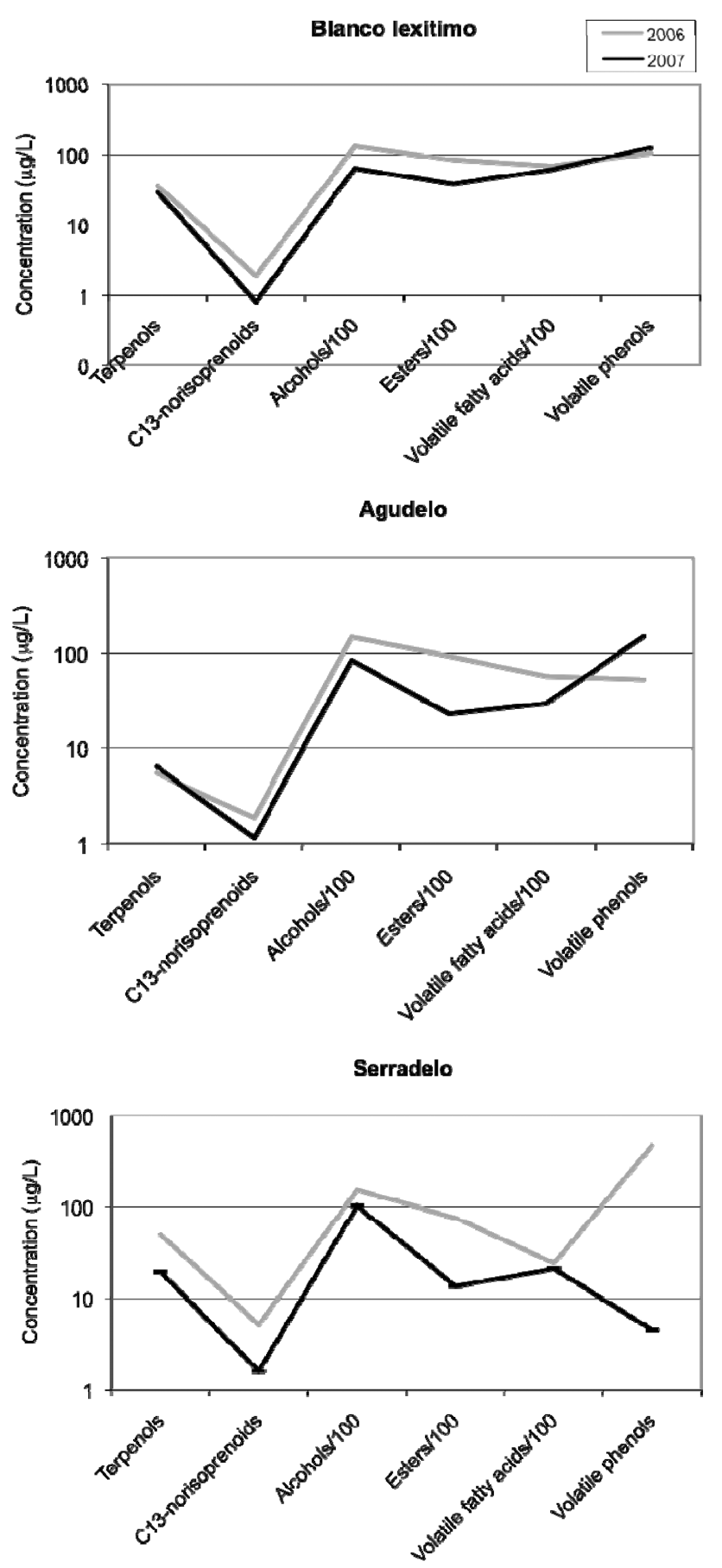

Fig. 1. Volatile composition of Blanco lexítimo, Agudelo and Serradelo wines of Betanzos from 2006 and 2007 vintages.

from Betanzos (Fig. 2). The first $P C A$ (Fig. 2A) shows the varietal compounds where the first two principal components accounted for $92.60 \%$ of the total variance $(71.70 \%$ and $20.89 \%$, respectively). The first principal component (Prin1) was characterised by a higher amount of $\alpha$-terpineol, nerol and $\beta$-damascenone attributes, with a positive loading. For the second principal component (Prin2), the attribute linalool was present with high contribution in the positive loading. The effect of cultivar was very important when the varietal compounds were analyzed.

\section{A Observations (axes F1 and F2: $92.60 \%$ )}

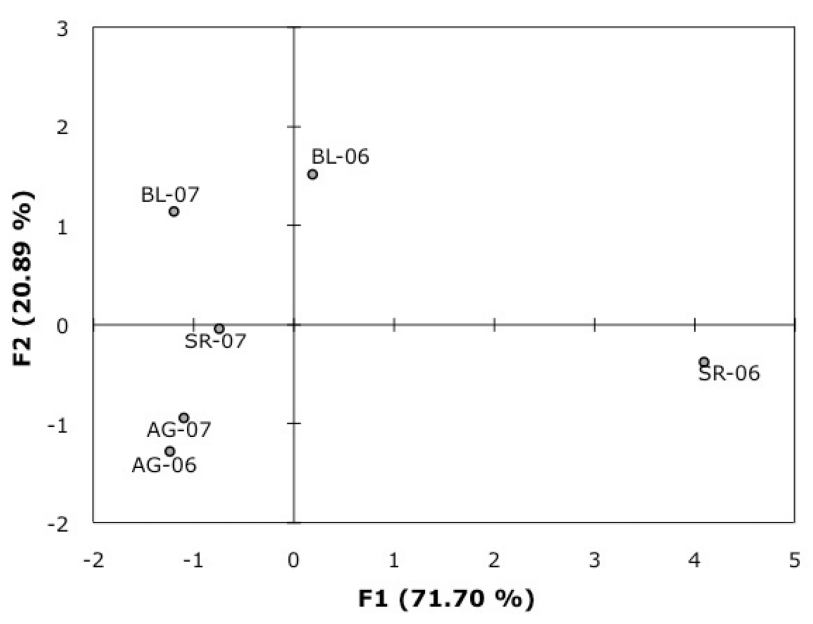

B Observations (axes F1 and F2: $71.40 \%$ )

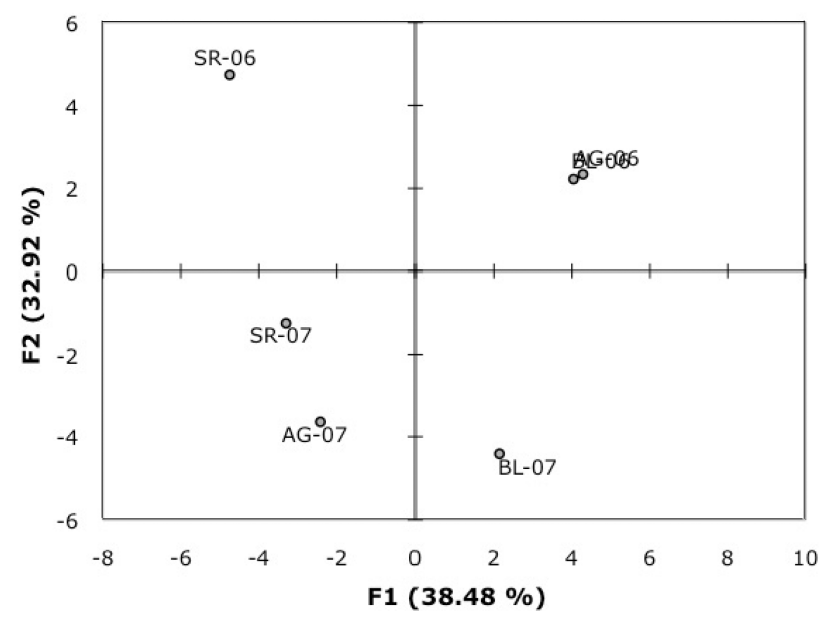

Fig. 2. Principal component analysis $(P C A)$ for volatile compounds from Blanco lexítimo (BL), Agudelo (AG) and Serradelo (SR) wines cultivated from the 2006 and 2007 vintages: A) Varietal compounds and B) all volatile compounds.

The second PCA (Fig. 2B) shows all volatile compounds. The first two principal components accounted for $71.40 \%$ of the total variance $(38.48 \%$ and $32.92 \%$, respectively). The first principal component (Prin1) was characterised by 1-butanol, ethyl hexanoate, ethyl decanoate and decanoic acid attributes, with a positive loading. For the second principal component (Prin2), the attributes isoamyl acetate, hexyl acetate and 2-phenylethyl acetate showed positive loading and 2-phenylethanol and diethyl succinate showed negative loading. In this case the effect of vintage was shown when the fermentative compounds were studied.

In order to assess the influence of the compounds studied on overall wine aroma, the $O A V s$ were calculated by dividing the concentration of each compound by its perception threshold. Only the compounds with an $O A V$ greater than 1 contribute individually to the wine aroma ${ }^{10}$. Other authors used different methods to establish the 
Table III. Odour activity values $(O A V)$ of volatile compounds with more influence on the aroma of wines from Blanco lexítimo, Agudelo and Serradelo varieties in consecutive vintages, 2006 and 2007.

\begin{tabular}{|c|c|c|c|c|c|c|c|c|}
\hline \multirow[b]{2}{*}{ Compounds } & \multirow[b]{2}{*}{ Sensory descriptor } & \multirow{2}{*}{$\begin{array}{c}\text { Odour threshold } \\
(\mu \mathrm{g} / \mathrm{L})^{*}\end{array}$} & \multicolumn{2}{|c|}{ Blanco lexítimo } & \multicolumn{2}{|c|}{ Agudelo } & \multicolumn{2}{|c|}{ Serradelo } \\
\hline & & & 2006 & 2007 & 2006 & 2007 & 2006 & 2007 \\
\hline Linalool & aniseed, roses, floral & 25 & 1.08 & 1.02 & 0.10 & 0.09 & 0.58 & 0.54 \\
\hline$\beta$-Damascenone & geranium, raisin-like, flowers & 0.045 & 41.20 & 17.76 & 41.26 & 25.16 & 113.68 & 35.56 \\
\hline Ethyl butyrate & papaya, butter, sweetish, apple & 20 & 6.08 & 7.71 & 8.28 & 4.34 & 5.60 & 4.18 \\
\hline Ethyl 3-methylbutyrate & fruity, apple, sweetish & 3 & 5.03 & 0.30 & 7.21 & 0.85 & 1.98 & 0.57 \\
\hline Isoamyl acetate & banana, apple, estery, solvent & 30 & 8.94 & 62.95 & 6.78 & 45.70 & 4.71 & 15.36 \\
\hline Ethyl hexanoate & apple, fruity, sweetish & 14 & 33.01 & 24.99 & 30.66 & 14.95 & 8.80 & 14.63 \\
\hline Ethyl octanoate & apple, fruity, sweetish & 5 & 164.03 & 156.94 & 143.50 & 49.51 & 27.86 & 46.83 \\
\hline $2+3$ Methylbutyric acid & cheese, old hops, sweaty & 34 & 1.45 & 1.47 & 2.80 & 1.90 & 0.80 & 0.93 \\
\hline Butyric acid & buttery, cheese, sweaty & 173 & 2.93 & 2.05 & 4.65 & 1.03 & 5.56 & 1.16 \\
\hline Hexanoic acid & goaty, fatty acid, vegetable oil & 420 & 2.28 & 2.62 & 2.25 & 1.12 & 0.67 & 0.90 \\
\hline Octanoic acid & goaty, fatty acid, vegetable oil & 500 & 8.38 & 8.17 & 7.56 & 4.09 & 1.62 & 2.45 \\
\hline Decanoic acid & waxy, tallowy, rancid, soapy & 1000 & 1.23 & 0.61 & 0.03 & 0.22 & 0.28 & 0.23 \\
\hline
\end{tabular}

* Odour descriptors and odour threshold reported in the literature ${ }^{5,17,25,30}$.

would-be impact odorant based on aroma index, when the concentration was at least $20 \%$ of the threshold unit ${ }^{26}$.

Table III shows the volatile compounds with an $O A V$ greater than 1, perception thresholds taken from literature, descriptors of each compound and the corresponding calculated $O A V$ for the three wines from two consecutive vintages, 2006 and 2007. Table III indicates that only 12 compounds out of the 35 compounds quantified can be found in the red and white young wines from Betanzos, at concentrations higher than their corresponding odour threshold, and possibly contribute to the wine flavour and aroma. The most aromatic wine was Blanco lexítimo with a total $O A V=275.64$ in the 2006 vintage and $O A V=$ 286.57 in the 2007 vintage, followed by Agudelo with a total $O A V=255.07$ and $O A V=148.96$ in the 2006 and 2007 vintages respectively.

Four ethyl esters (fruity aroma) were present at levels over the perception threshold in the three varieties. Esters contribute favourably to wine aroma as a fruity characteristic $^{5,26}$. Ethyl octanoate, isoamyl acetate, ethyl hexanoate and $\beta$-damascenone were the most powerful odorants for the white wines Blanco lexítimo and Agudelo from Betanzos. Isoamyl acetate was a more powerful odorant in all varieties from the 2007 vintages with respect to the 2006 . Ethyl octanoate ( $O A V$ of 46.83 in the 2007 vintage) and $\beta$ damascenone (OAV of 113.68 in the 2006 vintage) identified with fruity and floral aroma respectively, and were the most odorant for the red wine Serradelo. The compound $\beta$-damascenone, with a very low threshold, was found in higher concentrations in some wines from the Canary Islands, such Gual, Verdello, Marmajuelo, Listán and Malvasia wines, which explains the flowery and fruity aroma of these wines ${ }^{15}$.

Volatile fatty acids have been described by other authors ${ }^{26}$ with notes described as fruity, cheese-like and rancid. In our study $2+3$ methylbutyric acid, butyric and octanoic acids showed high concentrations for the three wines analyzed, but the contribution to the wine aroma was low with respect to the other compounds. These compounds were studied by Kotseridis and Baumes ${ }^{12}$ and were reported as impact odorants in several red Bordeaux wines.

Linalool, with aniseed, roses, floral and lemon aroma, was only present at a concentration above the odour threshold for Blanco lexítimo $(O A V=1.08$ in 2006 vintage and $O A V=1.02$ in 2007 vintage). Linalool is one of the most important monoterpenic compounds, because it also presents a low perception threshold ${ }^{14}$. Among terpenols, only linalool had an $O A V$ exceeding unity in Albariño wines from Galicia ${ }^{32}$ and Loureiro and Alvarinho from Portugal $^{23}$. The contribution of phenol volatiles to the wine aroma was not important in this study, however, the contribution to the aroma of compounds with near-unity $O A V$ s, cannot be ignored, because they can enhance some existing notes by synergy with other compounds ${ }^{8,14}$.

\section{CONCLUSIONS}

This work is a first study of the volatile composition of wines produced from the white varieties Blanco lexítimo and Agudelo and the red variety Serradelo grown in Betanzos and has determined the most powerful odorant compounds in these wines. Varietal and fermentative aroma compounds were identified and quantified in the free form. Twelve compounds were determined with more influence in the aroma of Betanzos wines from the 2006 and 2007 vintages. Ethyl octanoate, isoamyl acetate, ethyl hexanoate and $\beta$-damascenone were the most powerful odorants for the Blanco lexítimo and Agudelo white wines from Betanzos. Ethyl octanoate and $\beta$-damascenone (fruity and floral aroma respectively) were the most odorant for the Serradelo red wine. For the three monovarietal wines studied, this approach provided proof that white varieties from Betanzos were much richer than the red one. Blanco lexítimo is the most aromatic wine dominated by citric, banana, apple and pineapple aroma. Agudelo wine which is a minor aromatic, compared to Blanco lexítimo, presents high levels of fruity aromas and the red Serradelo wine was the most flowery wine, but with a minor aroma.

\section{ACKNOWLEDGEMENTS}

The authors thank Xunta de Galicia (Spain) and Adega Lorenzo Bescansa S.U.L. for financial support for this work.

\section{REFERENCES}

1. Aznar, M., Lopez, R., Cacho, J. F. and Ferreira, V., Identification and quantification of impact odorants of aged red wines 
from Rioja. GC-olfactometry, quantitative GC-MS, and odor evaluation of HPLC fractions. J. Agric. Food Chem., 2001, 49, 2924-2929.

2. Belitz, H. D. and Grosch, W., Food Chemistry ( $2^{\text {nd }}$ ed.), Springer-Verlag: Berlin, 1999, pp. 319-377.

3. Cabaroglu, T., Canbas, A., Lepoutre, J. P. and Gunata, Z., Free and bound volatile composition of red wines of Vitis vinifera $\mathrm{L}$. c.v. Öküzgözü and Bogazkere grown in Turkey. Am. J. Enol. Vitic., 2002, 53, 64-68.

4. Dieguez, S., Lois, C. L. Gomez, E. F. and de la Peña, M. L., Aromatic composition of the Vitis vinifera grape Albariño. LWTTechnologie, 2003, 36, 585-590.

5. Escudero, A., Gogorza, B., Melus, M. A., Ortin, N., Cacho, J. and Ferreira V., Characterization of the aroma of a wine from Macabeo. Key role played by compounds with low odour activity values. J. Agric. Food Chem., 2004, 52, 3516-3524.

6. Ferreira, V., López, R. and Cacho, J. F., Quantitative determination of the odorants of young red wines from different grape varieties. J. Sci. Food Agric., 2000, 80, 1659-1667.

7. Ferreira, V., Ortín, N., Escudero, A., López, R. and Cacho, J.F., Chemical characterization of the aroma of Grenache rose wines: Aroma extract dilution analysis, quantitative determination, and sensory reconstruction studies. J. Agric. Food Chem., 2002, 50, 4048-4054.

8. Freitas, V., Ramalho, P., Azevedo, Z. and Macedo, A., Identification of some volatile descriptors of the rock-rose-like aroma of fortified red wines from Douro demarcated region. J Agric. Food Chem., 1999, 47, 4327-4331.

9. Gómez-Míguez, M. J., Cacho, J. F., Ferreira, V., Vicario, I. M. and Heredia, F. J., Volatile components of Zalema white wines. Food Chem., 2007, 100, 1464-1473.

10. Guth, H., Identification of character impact odorants of different white wine varieties. J Agric. Food Chem., 1997, 45, 30273032 .

11. Henick-Kling, T., Acree, T. E., Krieger, S. A., Laurent, M. and Edinger, W. D., Wine East, 3rd Biotechnology Dossier: Vignevini, 1994, pp. 120-138.

12. Kotseridis, Y. and Baumes, R., Identification of impact odorants in Bordeaux red grape juice, in the commercial yeast used for its fermentation, and in the produced wine. J Agric. Food Chem., 2000, 48, 400-406.

13. Lambrechts, M. G. and Pretorius, I. S., Yeast and its importance to wine aroma. S. Afr. J. Enol. Vitic., 2000, 21, 97-129.

14. López, R., Ferreira, V., Hernández, P. and Cacho, J. F., Identification of impact odorants of young red wines made with Merlot, Cabernet Sauvignon and Grenache grape varieties: a comparative study. J. Agric. Food Chem., 1999, 79, 1461-1467.

15. Lopez, R., Ortin, N., Pérez-Trujillo, J. P., Cacho, J. and Ferreira, V., Impact odorants of different young white wines from the Canary Islands. J. Agric. Food Chem., 2003, 541, 3419-3425.

16. Marais, J., Terpenes in the aroma of grapes and wines. A review. S. Afr. J. Enol. Vitic., 1983, 42, 49-60.
17. Meilgard, M. C., Flavour chemistry of beer. Part II: flavour and threshold of 239 aroma volatiles. Tech. Q. Master Brew. Assoc. Am., 1975, 12, 151-168.

18. Moyano, L., Zea, L., Moreno, J. and Medina, M., Analytical study of aromatic series in sherry wines subjected to biological aging. J Agric. Food Chem., 2002, 50, 7356-7361.

19. Nurgel, C., Erten, H., Canbas, A., Cabaroglu, T. and Selli, S., Influence of Saccharomyces cerevisiae strains on fermentation and flavor compounds of white wines made from cv. Emir grown in Central Anatolia, Turkey. J. Ind. Microbiol. Biotechnol., 2002, 29, 28-35.

20. O.I.V., Recueil des méthodes internacionales d'analyse des vins et des moûts. Office Internetional de la Vigne et du Vin : Paris, 1990.

21. Oliveira, J. M., Araújo, I., Pereira, O. M., Maia, J. S., Amaral, A. J. and Maia, M. O., Characterization and differentiation of five "Vinhos Verdes" grape varieties on the basis of monoterpenic compounds. Anal. Chim. Acta, 2004, 513, 269-275.

22. Oliveira, J. M., Faria, M., Sá, F., Barros, F. and Araújo, I. M., $\mathrm{C}_{6}$-alcohols as varietal markers for assessment of wine origin. Anal. Chim. Acta, 2006, 563, 300-309

23. Oliveira, J. M., Oliveira, P., Baumes, R. L. and Maia, M. O., Volatile and glycosidically bound composition of Loureiro and Alvarinho wines. Food Sci. Technol. Int. 2008, 14, 341-353.

24. Rapp, A. and Mandery H., Wine aroma. Experientia, 1986, 42, 873-884.

25. Ribereau-Gayon, P., Glories, Y., Maujean, A. and Dubourdieu, D., Varietal aroma. In: Handbook of Enology. Volume 2 - The chemistry of wine and stabilization and treatments, John Wiley \& Sons Ltd: Chichester: England, 2000, pp. 187-206.

26. Rocha, S. M., Rodrigues, F., Coutinho, P., Delgadillo, I. and Coimbra M. A., Volatile composition of Baga red wine. Assessment of the identification of the would-be impact odorants. Anal. Chim. Acta, 2004, 513, 257-262.

27. Sanchez Palomo, E., Diaz-Maroto, M. C., Gonzalez Viñas, M. A., Soriano-Pérez, A. and Pérez-Coello, M. S., Aroma profile of wines from Albillo and Muscat grape varieties at different stages of ripening. Food Chem., 2007, 18, 398-403.

28. Sauvageot, F. and Vivier, P., Effects of malolactic fermentation on sensory properties of four burgundy wines. Am. J. Enol. Vitic., 1997, 48, 187-192.

29. Schreier, P., Flavor composition of wines: a review. CRC Critical Rev. Food Sci. Nutr., 1979, 12, 59-111.

30. Simpson, R. F. and Miller, G. C., Aroma composition of Chardonnay wine. Vitis, 1984, 23, 143-258.

31. Swiegers, J. H. and Pretorius, I. S., Yeast modulation of wine flavour. Adv. Appl. Microbiol., 2005, 57, 131-175.

32. Vilanova, M. and Sieiro, C., Determination of free and bound compounds in Albariño wine. J. Food Comp. Anal., 2006, 19, 694-697.

(Manuscript accepted for publication December 2008) 